Review

\title{
Corona Virus Disease 2019 (COVID-19) Pandemic Up-to-Date Facts, Opportunities and Challenges: A review on Cases in Ethiopia
}

\author{
Chanie Derso ${ }^{*}$
}

Department of Biotechnology, School of Bioscience and Technology/College of Natural Science, Wollo University, e_mail: chaniederso@gmail.com

\begin{abstract}
There are many types of coronavirus on the bases of important hosts including human, rat, turkey, rabbit, etc. The virus looks like a crown or corona of the sun with its round projection, spike. Now a day, newly emerged coronavirus disease (COVID 19) was first detected at Wuhan, China in December 2019 and it became a public health emergency international concern. Although a couple of researches has been conducting, much secretes of the virus and disease is still not understood and not reached a common understanding yet. However, sharing basic information is crucial based on the existing published research articles and updated information. Therefore, this review aimed to draw attention to the COVID 19 pandemic facts, opportunities, and challenges based on up to date information on cases in Ethiopia. Accordingly, the coronavirus is a single-stranded, nonsegmented RNA genome virus. Two third of the genome (5'end) consists of two genes that code nonstructural proteins and the other 2-7 genes (3' end) code structural proteins including spike, envelope, membrane, and nucleocapsid. The virus transmits from animal to human and suggested as it might be originated from a bat and/or seafood. Coronavirus transmit human to human by direct contact and droplets during coughing and sneezing and common symptoms like fever, dry cough, and tiredness, short breathing, etc. can be seen from the patient. So that stay at home and social distancing are the most practicing pre-prevention methods. The disease causes high economic loss, face to face education closure, community cultural practice, and mass gathering activities are prohibited. However, various charity associations and creativities found increase than before. To this end, peoples should accept and follow governmental advice and instructions to escape from the pandemic.
\end{abstract}

Keywords: Coronavirus; Prevention ; Species; Symptom; Virus origin

\section{Introduction}

The Coronaviruses (CoVs) are species of virus belonging to Order (Nidovirales), family (Coronaviridae, Arteriviridae, Roniviridae, and Mesoniviridae) (Zirkel et al., 2011), genus (Alpha coronavirus, Beta coronavirus, Gamma coronavirus, and Delta coronavirus) (Gorbalenya et al., 2006). They cause a variety of diseases in mammals and birds ranging from enteritis in cows and pigs and upper respiratory disease in 
chickens to potentially lethal human respiratory infections (Du et al., 2009). Alpha Coronavirus (HCV-229E and HCoVNL63) infect humans; Beta Coronavirus (SARS-CoV, HCV-OC43, HCV-HKU1, and MERS-CoV, Murine coronavirus (MHV) and Bovine Coronavirus (BCoV)) infect mammalians, widely mice and human; Gamma Coronavirus is specific to Birds and Delta Coronavirus (HKU11, HKU12, HKU13) is with mammals to birds (Susanna et al., 2012). Besides, Na et al. (2020) reported that several coronaviruses can infect humans, the globally endemic human coronaviruses HCV-229E, HCV-NL63, HCV-HKU1 and HCV-OC43 that tend to cause mild respiratory disease, and the zoonotic Middle East respiratory syndrome coronavirus (MERS$\mathrm{CoV}$ ) and severe acute respiratory syndrome coronavirus (SARS-CoV) that have a higher case fatality rate. As Chen et al. (2020) reviewed, there are various hosts (Table 1).

There are many types of coronaviruses in association with hosts. The exemplary coronaviruses include avian infectious bronchitis virus (IBV), mouse hepatitis virus (MHV), porcine transmissible gastroenteritis virus (TGEV), bovine coronavirus (BCV), human coronavirus (HCV), feline infectious peritonitis virus (FIPV), rat sialodacryoadenitis virus (SDAV), turkey coronavirus (TCV), rabbit coronavirus (RCV), and several viruses of other animal species (Lai, 1990).

The first coronavirus, avian infectious bronchitis virus, was isolated by Fred Beaudette in 1937 (Beaudette, 1937) followed by the isolation of the prototype murine coronavirus strain JHM was reported in 1949 (Bailley et al. (1949) and as Cauchemez et al. (2013) and Cui et al. (2019) stated, two novel $\beta$ CoVs, (SARS $\mathrm{CoV}$ in 2002 and MERS-CoV in 2012) were isolated and these viruses can cause severe human diseases (Cheng et al. (2007; Chan et al. (2015). In 2019, a newly emerged coronavirus disease 2019 (COVID-19), caused by the COVID-19 virus, was first detected in Wuhan, China, in December 2019 and became a public health emergency of international concern. Even though no specific animal association was identified, it is confirmed that the outbreak of the coronavirus epidemic was associated with the Huanan South China Seafood Marketplace (WHO, 2020).

Thereafter, the coronavirus infection continues to swell by thousands, new infections in a single day reaches its highest point and now infecting millions of people in the world. No continent has been able to escape to this virus. As reported by WHO on 14 May 2020, there are above 4, 307,287 causes, and 295,101 deaths globally, covering 216 countries, up to date. In Ethiopia, the first coronavirus case was reported on 13 March 2020 with one Japanese citizen. To date, five deaths and 120 recovered were reported out of 365 cases in Ethiopia (Ethiopian ministry of health, April 15, 2020).

Following as coronavirus is a newly emerged disease, many rapid types of research have conducted by various scholars, but many secrete of the virus and disease are still not understood and not reached a common understanding yet. Genomic structure and function, gene replication and expression; epidemiology and transmission, pathogenesis; economic impacts, and traditional medicine trial against the virus are among 
research efforts regard to the coronavirus. Therefore, it is vital to share the basic information from existed published research articles and updated information to the date. Thus, the aim of this review paper was to draw attention to the COVID 19 pandemic facts, opportunities, and challenges based on up to date information on cases in Ethiopia.

Table 1: Classification of Corona Virus and important hosts

\begin{tabular}{|c|c|c|c|c|c|}
\hline Order & Family & Subfamily & Genus & Host & Remark \\
\hline \multirow{9}{*}{ Nidovirales } & \multirow{6}{*}{ Coronaviridae } & \multirow{4}{*}{ Coronavirinae } & $\alpha-\mathrm{COV}$ & Human, Pig, Cat, & \multirow{9}{*}{$\begin{array}{l}\text { The Coronavirus } \\
\text { species and the } \\
\text { observed symptoms } \\
\text { are various for each } \\
\text { host. }\end{array}$} \\
\hline & & & $\beta-\mathrm{COV}$ & $\begin{array}{c}\text { Human, Cow, Horse, } \\
\text { Mouse }\end{array}$ & \\
\hline & & & $\mu-\mathrm{COV}$ & Whale, Chicken & \\
\hline & & & $\delta$-COV & Bulbul, sparrow & \\
\hline & & & Torovirus & & \\
\hline & & Torovirinae & Bafinivirus & & \\
\hline & Arteriviridae & & Arterivirus & & \\
\hline & Roniviridae & & Okarivirus & & \\
\hline & Mesoniviridae & & $\alpha$ Mesonivirus & & \\
\hline
\end{tabular}

\section{Name Assigning of Coronavirus}

The name "coronavirus," coined in 1968, is derived from the "corona” like or crown-like morphology observed for these viruses in the electron microscope (Tyrrel et al., 1968). As stated on the review of Woo et

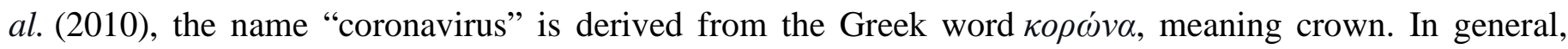
scientists gave the name for coronavirus from the solar atmosphere. That is, the sun has three atmospheres namely Chromospheres, photosphere, and Corona. The third atmosphere, corona, produces the highest heat, about 2 million $0 K$, and the shape of this atmosphere looks like a crown with zigzag like round projections. Similarly, the coronavirus causes higher body temperature in the patient and has a crown-like morphology when observed with a microscope (Oral presentation). In addition, Lai (1990) reviewed that the coronavirus resembling the corona of the sun. The WHO announced that the official name of the 2019 novel coronavirus is coronavirus disease (COVID-19) (WHO, 2020). From here, 'CO' stands for Corona, 'VI' for Virus and 'D' for Disease which emerged in December 2019.

\section{Biomolecular Structure of Coronavirus}

Coronavirus possesses a single strand, non-segmented, positive-sense RNA genome ranging from 26 to $32 \mathrm{~kb}$ in length (Su et al., 2016). As indicated in the other study, the coronavirus posses the largest genomes, 26.4 
kb to $31.7 \mathrm{~kb}$, among all known RNA viruses (Mihindukulasuriya et al., 2008). The coronavirus bind to the receptor via spike enters the host cytoplasm (Bosch et al., 2003), and releases the RNA genome into the host (Lai et al., 1984). The RNA genome is complexed with the basic nucleocapsid (N) protein to form a helical capsid, found within the viral membrane (Bond et al., 1979). This genome consists of seven genes that organized into 5' non-structural protein-coding regions comprising the replicase genes (gene 1), which cover two-thirds of the genome and 3' structural and non-essential accessory protein-coding regions comprising the gene 2-7 (Susan, 2005; Masters, 2006).

The replicase gene 1 products are encoded two open reading frames (ORFs), $1 \mathrm{a}$ and $1 \mathrm{~b}$ which translated into polypeptides, pp1a and pp1b. The pp1a and pp1b are consisting of non-structural proteins (nsp1-nsp16) and use variously (Baranov et al., 2005). Sub genomic RNAs, where Gene-2 to Gene-7 transcribed and encode the major viral structural proteins like a spike (S), an envelope protein (E), membrane protein (M), nucleocapsid protein (N) which are essential for different functions (Stertz et al., 2007).

Coronaviruses have five structural proteins namely Spike (S), Membrane (M), Envelope (E) glycoproteins, Hemagglutinin Esterase (HE), and Nucleocapsid (N) protein (figure 1). All virions possess all enveloped proteins and N protein, but HE presents only in some beta coronaviruses (Lissenberg et al., 2005). The spike (S glycoprotein), located outside, bind the virions to specific surface receptors in the plasma membrane of the host cell (Lewicki and Gallagher, 2002) while M proteins which glycosylated in the Golgi apparatus (De Haan et al., 1998), plays a key role in regenerating virions in the cell (Escors et al., 2001). The envelope (E glycoprotein), composed of approximately 7 to 109 amino acids (Raamsman et al., 2000), use in the assembly and morphogenesis of virions within the cell (Baudoux et al., 1998). The Nucleocapsid (N protein) plays an important role in virion structure, replication, and transcription of coronaviruses (Stertz et al., 2007).

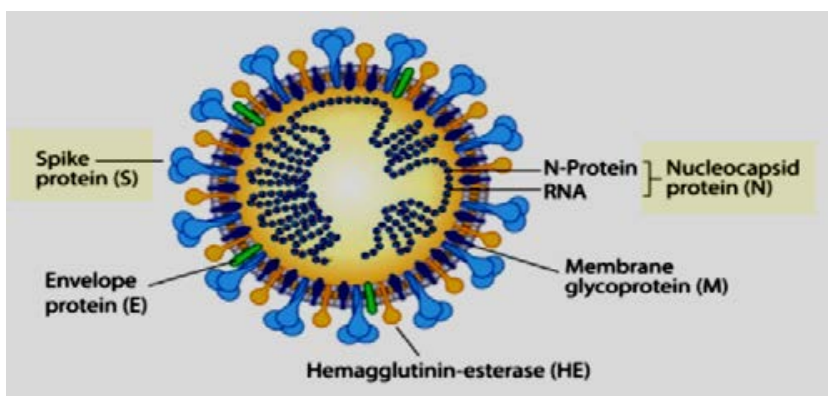

Fig 1. Structure of Coronavirus

\section{Coronavirus Origin and Transmission}

Evidence suggesting that the coronaviruses have their distinguishing origin. For instance, alpha CoVs and beta CoVs originated from bats and rodents while delta CoVs and gamma CoVs were from avian species (Cascella et al., 2020). Coronavirus can transmit from animal to human when there is direct contact to host 
animal and consumption of suspected animals without any roasting. The genome sequencing results and evolutionary analysis of Zhou et al. (2012) showed that bat has been suspected as a natural host of virus origin, and SARS-CoV-2 might be transmitted from bats via unknown intermediate hosts to infect humans.

As mentioned in the review of Guo et al. (2020), human-to-human transmission of SARS-CoV-2 occurs mainly between family members, including relatives and friends who intimately contacted with patients or incubation carrier. Coronaviruses are usually transmitted by direct contact through large respiratory droplets (ECDC, 2020). The other study also added that coronavirus transmitted from human-to-human by respiratory droplets from sneezing, coughing, and aerosols, with symptomatic people being the major source of transmission (Li et al., 2020). Those droplets can land on objects and surfaces around the person such as tables, doorknobs, and handrails. Due to this, people can become infected-by touching these objects or surfaces, then touching their eyes, nose, or mouth (WHO, 2020). Besides researchers (Nanshan and Lanjuan, 2020) has been confirmed the existence of live SARS-CoV2 in the stool specimen of the patients. In general, human-to-human transmission through close contact is the most common transmission mode for 2019-CoV.

\section{COVID 19 Symptoms}

COVID 19 may cause various symptoms such as pneumonia, fever, breathing difficulty, and lung infection (WMHC, 2020). According to the updated information of WHO in April 2020, the most common symptoms of COVID-19 are fever, dry cough, and tiredness. Other symptoms that are less common and may affect some patients include aches and pains, nasal congestion, headache, conjunctivitis, sore throat, diarrhea, loss of taste or smell, or a rash on skin or discoloration of fingers or toes. These symptoms are usually mild and begin gradually. Some people become infected but only have very mild symptoms. Older people, and those with underlying medical problems like high blood pressure, heart and lung problems, diabetes, or cancer, are at higher risk of developing a serious illness.

\section{COVID-19 Prevention}

Without trying to do, no vaccine is currently available, and therefore, there is no specific antiviral treatment recommended for COVID-19. The treatment is symptomatic, and oxygen therapy represents the major treatment intervention for patients with severe infection (Wang et al., 2020). So far, considering the lack of effective treatments for the virus, prevention is the best practice in order to reduce the impact (Adhikari et al., 2020). To do so, WHO (2020) and CDC (2020) indicated the following main measures: cover coughs and sneezes with tissues or bent elbow, use face masks, avoid contact with infected people, wash hands regularly with soap or disinfection with hand sanitizer at least for 20 seconds, maintain an appropriate distance (at least $2 \mathrm{~m}$ ) from people, avoid touching eyes, nose, and mouth with unwashed hands and following advice from healthcare. Currently in Ethiopia, stay at home, social distancing, hand washing, and stay in quarantine /self-isolation/ are kept in practice. 
The quarantine period is various. In the case of Ethiopia, the people who enter to Ethiopia by any means and those suspected have stayed for 14 days in the recommended safe quarantine area. Later on, they have diagnosed for COVID 19 and will be released to the public if free, otherwise hospitalized. Jiang et al. (2020) suggested that the official 14-day quarantine period only captured $88.5 \%$ of the population developing Covid19 and implementation of the 21-day quarantine period for everybody will capture $98.3 \%$ of the cases. Furthermore, developing countries like Ethiopia must have a strong pre-protection of the pandemic before spreading into the larger area by insuring self-isolation.

\section{COVID 19 Challenges}

COVID 19 is one of the greatest challenges to human beings in the history, since the pathogen of SARS-CoV2 is a new coronavirus, differed from either SARS-CoV or MERS-CoV in terms of biological characteristics and transmissibility (Chen et al., 2020). There is little knowledge of the pathogen and pathogenesis, no effective drugs or vaccine against the virus infection. Currently, it is understood that the pre-prevention methods for COVID 19 are staying at home, social distancing, and handwashing which have tried to experience in Ethiopia. Due to administratively implementing locked down measures, the following challenges have resulted:

Economic Loss: The COVID 19 emergency has already transformed into an economic and labor market shock, impacting the production of goods and services, consumption, and investment. Following travel prohibits, border closures, and quarantine measures, many workers cannot carry out their jobs. Consumers in many economies are unable to purchase goods and services. Given the current environment of uncertainty and fear, enterprises are likely to delay investments, purchases of goods, and the hiring of workers. There is also a significant rise in unemployment and underemployment due to the virus (ILO, 2020). According to UNESCO (2020), cultural events canceled, institutions closed, heightened risk of looting of sites and poaching at natural sites, artists unable to make ends meet and the tourism sector greatly affected due to the COVID-19 on the cultural sector around the world. This also has a negative impact on social, economic, and political issues.

Community Cultural Practices prohibition: Culture makes us resilient, gives us hope, reminds us that we are not alone. Most of the time, Ethiopians live, eat, drink, and share things together during holydays, weeding, and some other cultural events. Due to the emergency of COVID 19, such living styles have limited only with a single-family who already lived together. According to UNESCO (2020), COVID-19 has affected cultural practices like ceremonies and impacting communities everywhere. Along with the tourism industry, cultural and creative sectors are among the most affected by the current coronavirus crisis (OECD, 2020). 
Face to Face Education Closure: Due to the spreading of COVID 19 alarmingly, schools, colleges, universities, and other religious education institutions have obligated to suspend their face to face education to control the pandemic. Technology-based e-learning and evaluation are also difficult for developing countries due to limited technology resources. Furthermore, each parent, student, and educational institution (schools, colleges, and universities) may not have enough and equivalent resources to facilitate online teaching for the immediate effect. For instance, once study by Sintema (2020) hypothesized that COVID-19 would negatively impact the performance of students in the 2020 Grade 12 national examinations especially for mathematics, science, and design and technology subjects. Besides, Sahu (2020) indicated the difficulty to teach and evaluate practical laboratory courses, music, and arts.

Mass Gathering Activities Cancelation: To mitigate the impact of COVID 19, mass gathering for various sporting activities such as the Olympic Games, and community recreational football are suspended and canceled. As indicated by BCW (2020), 78\% of host cities surveyed admit that they will suffer financial losses in 2020 due to the cancellation or postponement of sporting events in their city or region. Not only sporting activities but also cultural events (theatres, cinemas, concerts), Conferences, meetings, trade fairs, etc. are prohibited to limit virus transmission. Each of the above events was the source of income for individuals and the country and so that it resulted in economic loss for the country.

Limited Diagnosis kit: Developing countries like Ethiopia have faced the scarcity of diagnosis kits and protective materials for the coronavirus especially during the first case was reported. Besides, some hospitals have shifted to only COVID 19 cases and non-COVID 19 cases have got service at home via telephone communication which costs higher. Furthermore, tiny testing has been done. According to World Bank data, there are just 0.3 hospital beds for every 1,000 people in Ethiopia, compared to 3.4 in Italy, 6.5 in France, and 2.9 in the U.S. Only a few hundred intensive care units are believed to be available along with 435 ventilators. There may soon be a need for tens of thousands.

Depression and Anxiety increase: As WHO (2020) reported an increase in symptoms of depression and anxiety are already being reported in several countries with the COVID-19 pandemic. A study in Ethiopia in April 2020 reported a 3-fold increase in the prevalence of symptoms of depression compared to estimates from before the epidemic.

\section{Things as Opportunity}

Charity Associations Increase: Starting from the beginning of COVID 19 pandemic and state of emergency in Ethiopia, Life is becoming challenging for low-income families and those surviving on daily labors. Various charity associations, institutions, groups of peoples, and individuals highly initiate to provide sanitary materials and food items 
for those who can't afford it. Following the federal housing cooperation announcement for $50 \%$ house rent reduction, many people allow $50 \%$ rental payment while others permit to live without monthly rental payment till the pandemic is cleanout.

Creativity Increase: since the outbreak of the coronavirus pandemic, ventilators, face masks, and gloves have become preferred around the globe. Sourcing medical and personal protection equipment is a huge problem for poorer countries such as Ethiopia. The pandemic has encouraged creative minds and developed devices to combat COVID-19.

Sanitation Slightly Increase: hand wash materials have put at each gate of institution, workplace, corner of a street, and the village of Ethiopia for public use. Some governmental and private sectors have used sanitizers for their staff and customers when they go in and out. Furthermore, the main streets have sprayed with disinfectants.

Family Attachment increase: Following the principles of staying at home, most parents, those who were busy before, got a chance to treat their children.

\section{Conclusion}

Coronavirus is a family of viruses, which can cause severe diseases such as severe acute respiratory syndrome, Middle East respiratory syndrome, and the new coronavirus disease first appeared in 2019 in Wuhan, China, called COVID-19 and now it is public health emergency of international concern. It has shocked many people and rapidly spread worldwide, leaving countries facing highly variable routes of COVID-19 infections and deaths. The virus might originate from animals (bats) and then to humans. The common transmission among humans is through direct contact, touching contaminated materials and droplets during coughing, sneezing, and speak. Once the people infected, show most common symptoms (dry cough, fever, tiredness), less common symptoms (aches and pains, sore throat, diarrhea, conjunctivitis, headache, loss of taste or smell and a rash on the skin, or discoloration of fingers or toes) and also serious symptoms (difficulty breathing or shortness of breath, chest pain or pressure and loss of speech or movement). No vaccination or any medical treatments available. Therefore, countries like Ethiopia ordered to stay home, keep social distancing, and sanitize. To do so, face to face education, mass gathering activities, community cultural practices, etc. are prohibited till the pandemic is reduced. While doing this, developing countries including Ethiopia have got the great economic loss. However, people got a chance to develop creativity and many charity associations are enhanced. In general, peoples should manage themselves and apply government instructions to getaway from COVID 19. 


\section{References:}

Adhikari, S. P., Meng, S., Wu, Y.J., Mao, Y.P., Ye, R.X.,Wang, Q.Z., Sun, C., Sylvia, S., Rozelle, S. and Raat, H. (2020). Epidemiology, causes, clinical manifestation and diagnosis, prevention and control of coronavirus disease (COVID-19) during the early outbreak period: A scoping review. Infect. Dis Poverty 9: 29.

Bailey, O.T., Pappenheimer, A. M., Cheever, F. S. and Daniels, J. B. (1949). A murine virus (JHM) causing disseminated encephalomyelitis with extensive destruction of myelin. II. Pathology. J. Exp. Med. 90:195-212.

Baranov, P.V., Henderson, C.M., Anderson, C.B., Gesteland, R.F., Atkins, J.F., Howard, M.T. (2005). Programmed ribosomal frame shifting in decoding the SARSCoV genome. Virology. 332: 498-510. https://goo.gl/FjF2Sc.

Baudoux, P., Carrat, C., Besnardeau, L., Charley, B. and Laude, H.(1998). Coronavirus pseudo particles formed with recombinant $\mathrm{M}$ and $\mathrm{E}$ proteins induce alpha interferon synthesis by leukocytes. J Virol. 72: 8636-8643. https://goo.gl/Fzrwdb.

BCW (Burson Cohn and Wolfe) (2020). An Overview of the Impact of COVID-19 on Sporting Events. https://bcw-sport.com/wp-content/uploads/2020/04/Host-City-Survey-Impact ofCOVID-19-April-2020.pdf

Beaudette, F. (1937). Cultivation of the virus of infectious bronchitis. J Am Vet Med Assoc. 90: 51-60

Bond, C.W., Leibowitz, J. L. and Robb, J. A. (1979). Pathogenic murine coronaviruses. II. Characterization of virus-specific proteins of murine coronaviruses JHMV and A59V. Virology 94:371 384.

Bosch, B.J., Zee, R., Haan, C. A., Rottier, P.J. (2003). The coronavirus spike protein is a class I virus fusion protein: structural and functional characterization of the fusion core complex. J Virol. 77: 8801-8811. https://goo.gl/cMi6mZ.

Cascella, M., Rajnik, M., and Cuomo, A. (2020). Features, evaluation and treatment coronavirus (COVID19). Treasure Island (FL): StatPearls Publishing.

Cauchemez, S., Van Kerkhove, M.D., Riley, S., Donnelly, C.A., Fraser, C. and Ferguson, N. M. (2013). Transmission scenarios for Middle East respiratory syndrome coronavirus (MERS-CoV) and how to tell them apart. Euro Surveill. 18(24):pii: 20503.

CDC (Centers for Disease Control) (2019). Novel Coronavirus, Wuhan, China. 2020. Available online: https://www.cdc.gov/coronavirus/2019-ncov/prevent-getting-sick/prevention.html

Chan, J. F., Lau, S.K., To, K.K., Cheng, V.C., Woo, P.C. and Yuen, K.Y.. (2015). Middle East respiratory syndrome coronavirus: another zoonotic betacoronavirus causing SARS-like disease. Clin. Microbiol. Rev. 28, 465-522. 
Chen N, Zhou M, Dong X, Qu J, Gong F, Han Y, et al. Epidemiological and clinical characteristics of 99 cases of 2019 novel coronavirus pneumonia in Wuhan, China: a descriptive study. Lancet. 2020;395(10223):507-13.

Chen, Y., Liu, Q. and Guo, D. (2020). Emerging coronaviruses: Genome structure, replication, and pathogenesis. J. Med Virol. 92:418-423. https://doi.org/10.1002/jmv.25681.

Cheng, V. C., Lau, S. K., Woo, P. C. and Yuen, K. Y. (2007). Severe acute respiratory syndrome coronavirus as an agent of emerging and reemerging infection. Clin. Microbiol. Rev. 20, 660-694.

Cui, J., Li, F. and Shi, Z. L. (2019). Origin and evolution of pathogenic coronaviruses. Nat Rev Microbiol. 17(3):181-192.

De Haan, C. A., Kuo, L., Masters, P. S., Vennema, H., and Rottier, P. J. (1998). Coronavirus particle assembly: primary structure requirements of the membrane protein. Journal of virology, 72(8), 6838-6850.

Du, L., He, Y., Zhou, Y., Liu, S., Zheng, B.J. and Jiang, S. (2009). The spike protein of SARSCoV-a target for vaccine and therapeutic development. Nat Rev Microbiol. 7: 226-236. https://goo.gl/T2kyhu.

ECDC (European Centre for Disease Prevention and Control) (2020). Risk assessment: Outbreak of acute respiratory syndrome associated with a novel coronavirus, Wuhan, China;. Available from: www.ecdc.europa.eu/en/publications-data/risk-assessment-outbreak-acute-respiratory-syndromeassociatednovel-1.

Escors, D., Ortego, J. and Enjuanes, L.(2001). The membrane M protein of the transmissible gastroenteritis coronavirus binds to the internal core through the carboxyterminus. Adv Exp Med Biol. 494: 589-593. https://goo.gl/Erg1Yi.

Gorbalenya, A.E., Enjuanes, L., Ziebuhr, J. and Snijder, E. J. (2006). Nidovirales: evolving the largest RNA virus genome. Virus Research. 117: 17-37. https://goo.gl/A2FJCP.

Guo Y., Qing-Dong Cao, Q., Hong, Z.,Tan, Y., Chen, S., Jin, H., Tan, K., Wang, D. and Yan, Y. (2020). The origin, transmission and clinical therapies on coronavirus disease 2019 (COVID-19) outbreak - an update on the status. Military Medical Research,7:11.

Jiang, X., Niu,Y., Li, X., Li, L. , Cai, W., Chen Y., Liao, B. and Wang, E. (2020). Is a 14-day quarantine period optimal for effectively controlling coronavirus disease 2019 (COVID-19)? medRxiv preprint doi: https://doi.org/10.1101/2020.03.15.20036533.

Lai, M. M. (1990). Coronavirus: Organization, Replication and Expression Of Genome. Annu. Rev. Microbiol. 44:303-33.

Lai, M.M, Baric, R.S., Brayton, P.R., Stohlman, S.A. (1984). Studies on the Mechanism of RNA Synthesis of a Murine Coronavirus. Advances in Medicine and Biology. 173: 187-200. https://goo.gl/B0JChH. 
Lewicki, D. N. and Gallagher, T. M. (2002). Quaternary structure of coronavirus spikes in complex with carcinoembryonic antigen- related cell adhesion molecule cellular receptors. J. Biol Chem. 277: 1972719734. https://goo.gl/QTGQoI.

Li, Q., Guan, X., Wu, P., Wang, X., Zhou, L., Tong, Y. (2020). Early transmission dynamics in Wuhan, China, of novel coronavirus-infected pneumonia. N Engl J Med. doi: 10.1056/NEJMoa2001316.

Lissenberg, A., Vrolijk, M.M., van Vliet, A.L., Langereis, M.A., de Groot-Mijnes, J.D., Rottier, P.J., (2005). Luxury at a cost? Recombinant mouse hepatitis viruses expressing the accessory hem agglutinin esterase protein display reduced fi tness in vitro. $J$ Virol. 79: 15054-63. https://goo.gl/NT5Lp7.

Masters, P.S. (2006). The molecular biology of coronaviruses. Adv Virus Res. 66: 193-292. https://goo.gl/x66XSJ.

Mihindukulasuriya, K. A., Wu, G., St Leger, J., Nordhausen, R.W., Wang, D. (2008). Identification of a novel coronavirus from a beluga whale by using a panviral microarray. J. Virol. 82: 5084-5088.

Na, Z., Dingyu Z., Wenling, W., Xingwang L., Bo, Y., Jingdong, S., Xiang Z., Baoying, H., Weifeng, S., Roujian, L., Peihua, N., Faxian, Z., Xuejun, M., Dayan, W., Wenbo, X., Guizhen, W. and George, F. (2020). A novel coronavirus from patients with pneumonia in China, N Engl J. Med.

Nanshan Z. and Lanjuan L. (2020). The SRAS-COV-2 isolated from the stool specimens of patients with novel coronavirus-infected pneumonia. http://www.chinanews. com/gn/2020/0213/9090170.shtml.pdf. Accessed February 13, 2020.

OECD (Organisation for Economic Co-operation and Development), 2020. https://www.oecd.org/cfe/leed/culture-webinars.htm

Raamsman, M.J.B., Locker, J.K., de Hooge, A., de Vries, A.A., Griffi, G., Vennema. H., (2000) Characterization of the coronavirus mouse hepatitis virus strain A59 small membrane protein E. J Virol. 74: 2333 2342. https://goo.gl/GwygyF.

Sahu, P. (April 04, 2020). Closure of Universities Due to Coronavirus Disease 2019 (COVID-19): Impact on Education and Mental Health of Students and Academic Staff. Cureus 12(4): e7541. DOI 10.7759/cureus.7541.

Sintema, E. J. (2020). Effect of COVID-19 on the Performance of Grade 12 Students: Implications for STEM Education. EURASIA Journal of Mathematics, Science and Technology Education, 2020, 16(7), em1851 ISSN:1305-8223.

Stertz, S., Reichelt, M., Spiegel, M., Kuri, T., Sobrido, L, Sastre, A., (2007). The intracellular sites of early replication and budding of SARS coronavirus. Virology, 361: 304-15 https://goo.gl/LfTwph 
Stertz, S., Reichelt, M., Spiegel, M., Kuri, T., Sobrido, L., Sastre, A. (2007). The intracellular sites of early replication and budding of SARS coronavirus. Virology, 361: 304-15 https://goo.gl/LfTwph.

Su, S., Wong, G. and Shi, W. (2016). Epidemiology, genetic recombination, and pathogenesis of coronaviruses. Trends Microbiol. 24: 490-502.

Susan, R.W. and Sonia, N. (2005). Coronavirus pathogenesis and the emerging pathogen severe acute respiratory syndrome coronavirus. Microbiol Mol Biol Rev. 69: 635-664. https://goo.gl/dirC5y.

Susanna, K.P.L., Kenneth, S.M.L., Alan, K.L.T., Chung, T. S., Ming, W. and Choi, G. K. (2012). Recent Transmission of a Novel Alpha coronavirus, Bat Coronavirus HKU10, from Leschenault'sRousettes to Pomona Leaf Nosed Bats: First Evidence of Interspecies Transmission of Coronavirus between Bats of Different Suborders. J. Virol. 86: 11906-11918. https://goo.gl/Xafpnc.

Tyrrel, D. A., Almedia, J. D., Berry, D.M, Cunningham, C. H., Hamre, D., Hofstad, M.S., Malluci, L. and McIntosh, K. (1968). Coronavirus. Nature 220:650.

UNESCO (United Nations Education, Science and Cultural organization), (2020). Culture and COVID-19. https://en.unesco.org/sites/default/files/issue 1 in culture covid-19 tracker.pdf UNESCO (United Nations Education, Science and Cultural organization), (2020). UNESCO supports culture and heritage during COVID-19 shutdown https://en.unesco.org/news/unesco-supports-culture-and-heritage-during-covid-19$\underline{\text { shutdown }}$

Wang, H., Wang, S., and Yu, K. (2020). COVID-19 infection epidemic: The medical management strategies in Heilongjiang Province, China. Crit. Care 2020, 24, 107.

WHO (2020). Rational use of personal protective equipment for coronavirus disease 2019 (COVID-19). Interim guidance.

WHO (World Health Organization) (2020). Coronavirus Disease (COVID-19) Advice for the Public. Available online: https: //www.who.int/emergencies/diseases/novel-coronavirus-2019/advice-forpublic.

WHO (World Health Organization) (2020). UN Policy Brief on COVID-19 and the need for action on mental health. https://www.who.int/emergencies/diseases/novel-coronavirus-2019/events-as-theyhappen

WMHC (2020). Wuhan Municipal Health and Health Commission's Briefing on the Current Pneumonia Epidemic Situation in Our City. http://wjw.wuhan. gov.cn/front/web/showDetail/2019123108989. 
Woo, P.C.Y., Huang, Y., Lau, S.K.P., Yuen, K.Y. (2000). Coronavirus Genomics and Bioinformatics Analysis. Viruses 2, 1804-1820.

Zhou, P. Yang, X. L, Wang, X. G, Hu, B., Zhang, L., Zhang, W., (2020). A pneumonia outbreak associated with a new coronavirus of probable bat origin. Nature. https://doi.org/10.1038/s41586-020-2012-7.

Zirkel, F., Kurth, A., Quan, P. L., Briese, T., Ellerbrok, H., Pauli, G, (2011). An Insect Nidovirus Emerging from a Primary Tropical Rainforest. M Bio. 2: e00077-11. https:/goo.gl/bpBvNn. 